\title{
ANÁLISE MORFOMÉTRICA EM NEOTECTÔNICA: O EXEMPLO DO PLANALTO DE CAMPOS DO JORDÃO, SP
}

\author{
Silvio Takashi HIRUMA \\ Claudio RICCOMINI
}

\begin{abstract}
RESUMO
Mapas morfométricos e modelos digitais de terreno foram gerados utilizando-se técnicas de geoprocessamento com o intuito de subsidiar a análise neotectônica do Planalto de Campos do Jordão. Modelos digitais de terreno (MDT) permitiram uma visão global do relevo, realçando os diferentes níveis topográficos e as principais feições morfológicas, além de constituírem a base para a obtenção de parâmetros morfométricos. Mapas de sombreamento de relevo e de orientação de vertentes auxiliaram na identificação de lineamentos morfoestruturais, em complemento à análise de sensores remotos. A análise de lineamentos morfoestruturais permitiu a identificação das seguintes direções principais: NE-SW/ENE-WSW, coerentes com a estruturação regional pré-cambriana, e N-S/NW-SE que refletem uma estruturação mais recente. Tais direções correspondem a falhas de reativação com componentes normais e transcorrentes relacionadas a diferentes regimes de esforços neotectônicos. Os mapas morfométricos, em conjunto com a análise estrutural, indicam um forte controle tectônico na organização da rede de drenagem e na compartimentação do planalto. A distribuição espacial da densidade de drenagem, rugosidade de relevo, gradientes hidráulicos e superfícies de base permite a subdivisão do planalto em blocos menores, delimitados pelos principais lineamentos morfoestruturais. As técnicas mostraram-se adequadas para a identificação preliminar de áreas anômalas indicativas de controle neotectônico e podem ser adotadas em áreas onde dados geológicos e geomorfológicos básicos são escassos.

Palavras-chave: morfometria, modelo digital de terreno, neotectônica, Planalto de Campos do Jordão.
\end{abstract}

\section{ABSTRACT}

Morphometric maps and digital terrain models were created, using geoprocessing techniques, to assist neotectonic analyses in the Campos do Jordão Plateau. Digital terrain models permitted a general overview of the topography, highlighting the several topographic levels and the main morphological features, besides constituting the basis for morphometric parameters. Shadowed relief and slope orientation maps helped in the identification of morphostructural lineaments, complementing remote sensing data analysis. Morphostructural lineament analyses permitted the identification of the following trends: NE-SW/ENE-WSW, coherent with the regional Precambrian structures, and N-S/W-SE which reflect more recent structures. These lineament trends correspond to reactivation faults with normal and strike-slip components, related to different neotectonic stress regimes. Morphometric maps, in addition to structural analyses, revealed a tectonic control in the drainage network organization and compartimentalization of the plateau. The spatial distribution of drainage density, relief roughness, hydraulic gradients and isobase surfaces permitted the subdivision of the plateau into smaller blocks, delimited by the main trends of morphostructural lineaments. The techniques proved to be appropriate for the preliminary identification of anomalous areas that can indicate neotectonic control and can also be used in areas of sparce geological and geomorphological data.

Keywords: morphometry, digital terrain model, neotectonics, Campos do Jordão Plateau.

\section{INTRODUÇÃO}

A aplicação de análises morfométricas em neotectônica constitui uma importante ferramenta na identificação de descontinuidades no padrão de relevo e anomalias na rede de drenagem que podem evidenciar movimentações recentes (cf. DEFFONTAINES 1989, 1991; ZUCHIEWICZ 1991; ZUCHIEWICZ \& OAKS Jr. 1993; RODRIGUEZ 1993; SALVADOR \& RICCOMINI 1995; DEROIN \& DEFFONTAINES 1995 e JIANJUN et al. 1997). De modo geral, tais análises antecedem os trabalhos de campo e têm por finalidade a identificação preli- 
minar de áreas com maior probabilidade de ocorrência de registros de depósitos recentes e estruturas neotectônicas. O avanço de técnicas computacionais vem permitindo a obtenção de modelos digitais de terreno, parâmetros morfométricos e índices de correlação com maior rapidez e precisão. Técnicas de geoprocessamento vêm sendo utilizadas com maior freqüência na análise geomorfológica quantitativa (cf. DEFFONTAINES 1990, RILEY \& MOORE 1993, GONTIJO et al. 1998, JOHANSSON 1999).

Este estudo avalia o potencial da análise morfométrica para subsidiar estudos sobre neotectônica, a partir de técnicas de geoprocessamento, na área que abrange o frontão sudeste do Planalto de Campos do Jordão e parte da escarpa da Serra da Mantiqueira, ambas em terras paulistas, ocupando parcialmente os municípios de Campos do Jordão, Guaratinguetá e Pindamonhangaba (Fig. 1). Os resultados desta análise foram comparados com dados geológicos e geomorfológicos existentes para a região.

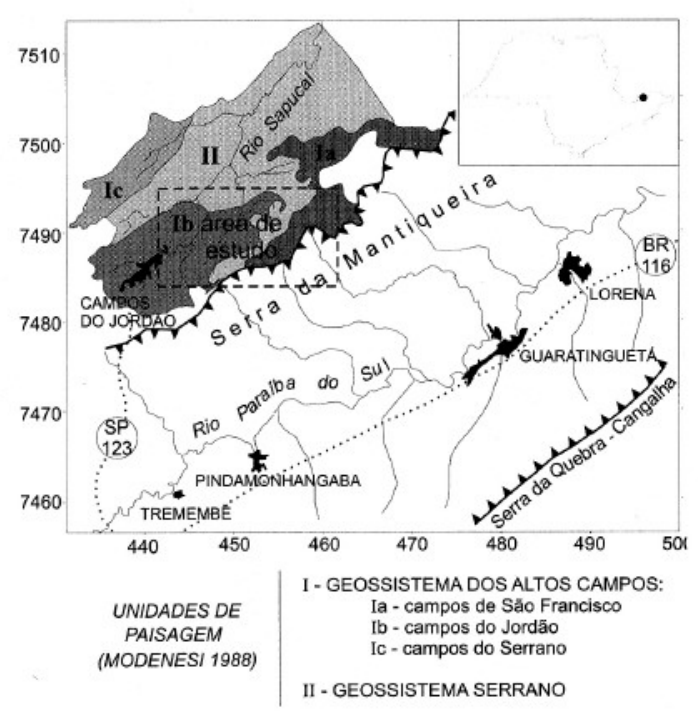

FIGURA 1 - Localização da área de estudo no contexto das unidades de paisagem definidas para o Planalto de Campos do Jordão (MODENESI 1988a).

O Planalto de Campos do Jordão, situado na porção sudoeste do bloco principal da Serra da Mantiqueira - leste de São Paulo e sul de Minas Gerais -, constitui uma das superficies cimeiras do Brasil de Sudeste (AB'SÁBER \& BERNARDES 1958, DE MARTONNE 1943), compondo os altos blocos de planaltos cristalinos definidos por AB'SÁBER (1956). A influência da tectônica recente no Planalto de
Campos do Jordão vem sendo discutida em diversos trabalhos, onde se destacam os de FREITAS (1951), RUELLAN (1952), ALMEIDA (1964), MODENESI (1980, 1983, 1988a, 1988b) e MODENESI-GAUTTIERI et al. (1997a,b). RUELLAN (1952) sustentava a hipótese da subdivisão do planalto em pequenos blocos falhados e basculados, separados por depressões de ângulo de falha. MODENESI (1980, 1983, 1988a, 1988b) distingue várias feições indicativas de tectonismo recente como capturas de drenagem ao longo da Zona de Cisalhamento de Jundiuvira, facetas triangulares e trapezoidais e anfiteatros suspensos na área do Morro da Pedra de Fogo e no Vale do Ribeirão do Fojo, entre outras. SAADI (1991) caracteriza o compartimento dos blocos da Serra da Mantiqueira pelo agrupamento de serras alongadas em direção principal SSW-NNE, constituindo os basculamentos dos blocos tectônicos para noroeste ou nordeste a tônica principal dessa morfologia. Mais recentemente, a integração de dados geomorfológicos e estruturais permitiu reconhecer a superposição de três regimes de esforços neotectônicos no Planalto de Campos do Jordão (HIRUMA 1999): o mais antigo (Pleistoceno Superior a Holoceno) corrresponde a um regime compressivo NW - SE relacionado a um binário transcorrente dextral, de direção $\mathrm{E}$ W, seguido por outro de extensão $\mathrm{E}-\mathrm{W}$ a NW$\mathrm{SE}$ e, finalmente, um regime de esforços compressivos de direção E-W a NW-SE, compatível com o regime atual de esforços horizontais máximos, obtidos a partir de dados geofísicos.

$\mathrm{O}$ presente trabalho integra o projeto "Evolução quaternária das cimeiras do Brasil de "Sudeste: o Planalto de Campos do Jordão" 'Instituto Geológico - SMA / Instituto de Geociências - USP) que tem por finalidade obter dados necessários à reconstituição espacial e temporal da evolução quaternária da paisagem das cimeiras do Brasil de Sudeste.

\section{ASPECTOS GEOLÓGICOS E GEOMORFOLÓGICOS}

O Planalto de Campos do Jordão está inserido na Região de Dobramentos Sudeste (ALMEIDA et al. 1976) incluindo rochas geradas no Ciclo Brasiliano e, em parte, rochas resultantes do retrabalhamento de rochas mais antigas. Os limites do planalto são essencial- 
mente tectônicos (HASUI et al. 1978, MODENESI 1988a); duas grandes falhas transcorrentes de direção NE e idade pré-cambriana a eopaleozóica reativadas delimitam o planalto: a Falha de Jundiuvira (HASUI et al. 1978), próxima da escarpa da Mantiqueira, e a Falha do Paiol
Grande (HASUI et al. 1978) ou de São Bento do Sapucaí (CAVALCANTE et al. 1979), no seu flanco norte. A figura 2 ilustra as principais estruturas neotectônicas e litotipos da área de estudo.

A partir do Jurássico Superior, a região

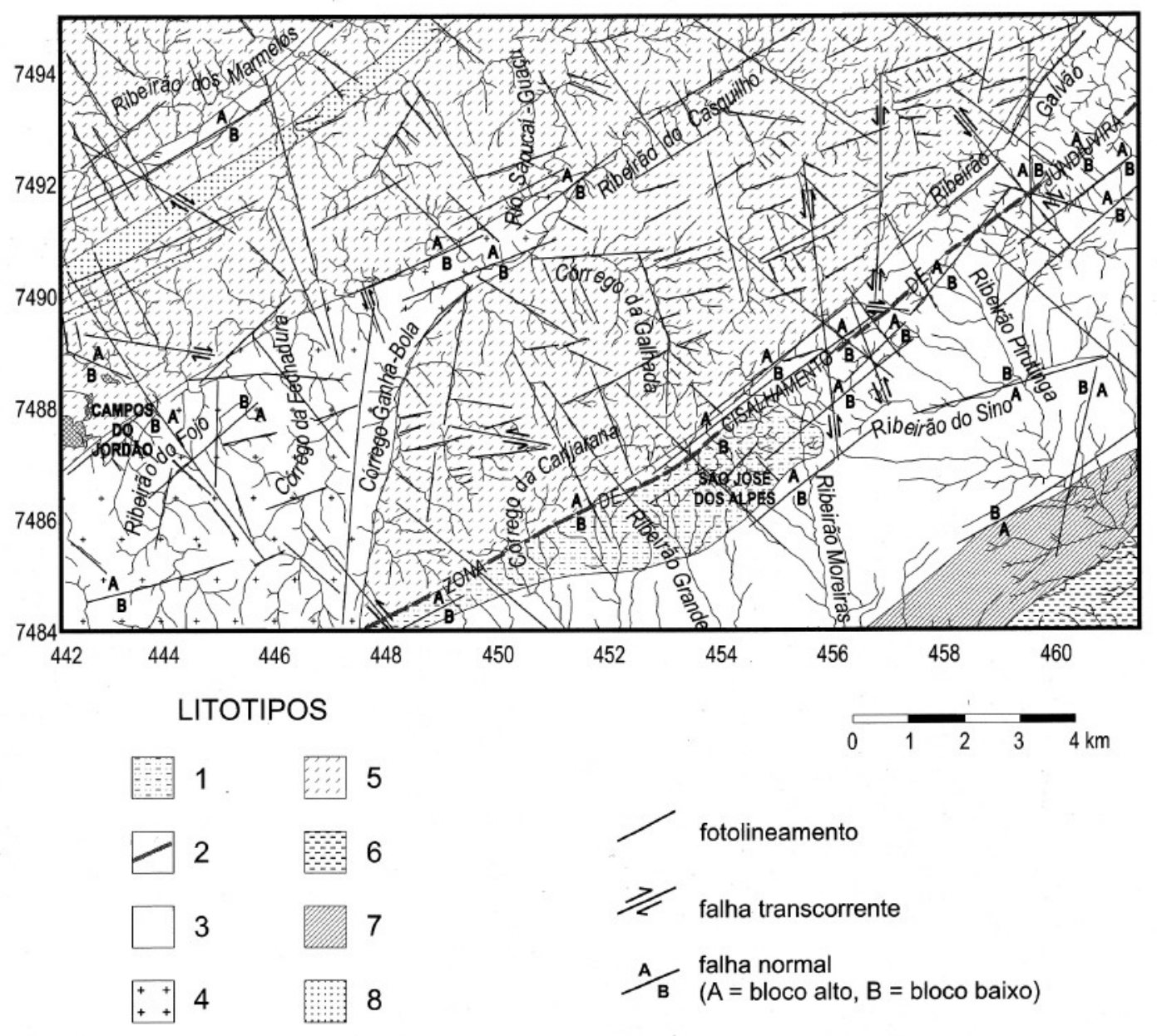

FIGURA 2 - Principais estruturas neotectônicas e litotipos do frontão sudeste do Planalto de Campos do Jordão. Litotipos: (1) Metaconglomerados polimíticos, metarenitos arcoseanos e metassiltitos (Formação Pico de Itapeva), (2) Ultramilonitos em zona de cisalhamento, (3) Predominância de milonito gnaisses, (4) Predominância de biotita granitos ( $3 \mathrm{a}$ e $3 \mathrm{~b}$ ), localmente miloníticos, com encraves de xistos feldspatizados e biotita gnaisses bandados, (5) Predominância de biotita gnaisses bandados, (6) Migmatitos estromáticos e biotita gnaisses bandados, (7) Predominância de biotita gnaisses porfiroblásticos e biotita xistos, (8) Predominância de muscovita quartzitos, por vezes miloníticos. Mapa geológico extraído de HIRUMA (1999), compilado de HASUI et al. (1978), CAVALCANTE et al. (1979) e MORAIS et al. (inédito).

foi submetida a fenômenos relacionados com a Reativação Wealdeniana (ALMEIDA 1967), melhor caracterizada como evento SulAtlantiano (SCHOBBENHAUS et al. 1984), que culminaram, no Cretáceo Inferior, com a abertura do Oceano Atlântico Sul. Movimentos verticais opostos - descendentes na Bacia de Santos e ascendentes na região continental vizi- nha (ALMEIDA 1967, ASMUS \& FERRARI 1978) - teriam importantes efeitos na porção continental. Durante o Paleógeno (EocenoOligoceno) a reativação normal de antigas zonas de cisalhamento originou uma importante feição tectônica: o Rift Continental do Sudeste do Brasil - RCSB - (RICCOMINI 1989), anteriormente denominado de Sistema de Rifts da Serra 
do Mar por ALMEIDA (1976). A evolução do rift resultou na configuração atual do relevo da porção leste do Estado de São Paulo, representada pelas Serras do Mar e Mantiqueira, como feições soerguidas e a Bacia de Taubaté, como feição abatida. Durante o Mioceno/pré-Pleistoceno teria ocorrido a acentuação do desnível topográfico entre os compartimentos, com o soerguimento do Planalto de Campos do Jordão a mais de $2.000 \mathrm{~m}$ (ALMEIDA 1976).

A altitude do planalto sofre um decréscimo de 6 a $7 \mathrm{~m}$ por $\mathrm{km}$ de sudeste $(2.050 \mathrm{~m})$ em direção ao norte e noroeste $(1.850 \mathrm{~m})$. Entre o divisor da Mantiqueira (1.900-2.007m) e o Vale do Rio Sapucaí (1.573 m em Vila Capivari), são identificados três níveis topográficos que se sucedem em altitudes de $1.800-1.820 \mathrm{~m}, 1.710-1.740 \mathrm{~m} \mathrm{e}$ 1.640-1.660 m (MODENESI 1988a). Os principais coletores do planalto - como o SapucaíMirim - apresentam traçados quase normais às estruturas regionais, fluindo de sul para norte, enquanto que a drenagem de menor hierarquia é essencialmente subseqüente, concordante com os principais lineamentos estruturais de direção ENE (ALMEIDA 1964).

A evolução quaternária nas áreas de cimeira do planalto resultou em um sistema de paisagem tropical adaptado às condições do clima de altitude - os altos campos (MODENESI 1980, 1983, 1988a, 1988b). A distribuição da vegetação caracteriza-se por um típico mosaico de mata e campo. Campos recobrem os topos dos interflúvios e o setor convexo das vertentes enquanto que a mata ocupa o setor retilíneo inferior das vertentes convexas, as vertentes retilíneas e os anfiteatros de erosão. São reconhecidas no Planalto de Campos do Jordão duas unidades de paisagem fisionomicamente heterogêneas: o geossistema dos altos campos e o geossistema serrano (Fig. 1). No geossistema dos altos campos, variações associadas a diferenças litológicas e ao grau de dissecação do relevo permitiram a individualização em três unidades: campos do Jordão, campos do Serrano e campos de São Francisco. Nos campos do Jordão e do Serrano predominam rochas maciças ou com xistosidade pouco marcada. Os campos de São Francisco, situados nas porções mais elevadas da borda sudeste do planalto (acima de $1.900 \mathrm{~m}$ ), caracterizam-se pelo relevo com baixa amplitude topográfica ( 40 a $50 \mathrm{~m}$ ), mamelonização generalizada das vertentes e maior heterogeneidade litológica. $O$ geossistema serrano res- tringe-se às áreas profundamente dissecadas pelos ribeirões dos Marmelos, Jacu e Coxim, que se encontram recobertas pela mata.

\section{AQUISIÇÃO E PROCESSAMENTO DOS DADOS}

A seguir são apresentados os métodos e técnicas utilizados na aquisição e processamento dos parâmetros morfométricos. Métodos manuais e automáticos de aquisição de dados foram mesclados. Técnicas de geoprocessamento foram utilizadas para geração de mapas morfométricos, modelos de elevação digital e cruzamento de dados.

Um modelo digital de terreno foi gerado a partir da digitalização de curvas de nível e pontos cotados das cartas topográficas Campos do Jordão e Delfim Moreira - escala 1:50.000 (IBGE). Os dados foram georreferenciados a partir de grid retangular, facilitando a aquisição dos dados em malhas quadráticas. O intervalo utilizado para a digitalização das curvas de nível variou conforme a declividade do terreno (de 20 em $20 \mathrm{~m}$ nas áreas mais planas e de $100 \mathrm{em} 100$ $\mathrm{m}$ nas áreas com maior declividade). A interpolação dos dados para a geração do modelo digital de terreno foi feita no programa SURFER (Golden Software). Adotou-se um grid de 111 linhas X 196 colunas (espaçamento de 100 metros) e o método de interpolação de krigagem, com raio de procura de $500 \mathrm{~m}$. Imagens realísticas de relevo foram geradas no programa SIS (FERRARI \& MANGIN 2000), que permite a manipulação da superfície tridimensional em tempo real, possibilitando a inspeção visual do conjunto do relevo a partir de diferentes pontos de vista e sombreamentos. O modelo digital de terreno constituiu a base para a elaboração das cartas de hipsometria, declividade, orientação de vertentes, sombreamento de relevo, rugosidade de relevo e perfis morfológicos.

Mapas de sombreamento de relevo, obtidos com diferentes azimutes e ângulos de iluminação, permitiram maior refinamento na extração de lineamentos morfoestruturais. Estes dados complementaram a análise de imagens de satélite (escalas 1:100.000 e 1:250.000) e de radar (escala 1:250.000), conforme método adotado nos trabalhos de LIU (1987) e RICCOMINI \& CRÓSTA (1988).

Os mapas de superficies de base, gradientes 
hidráulicos e densidade de drenagem foram elaborados a partir de cartas topográficas na escala 1:10.000 (TERRAFOTO/SEP). Para a elaboração destes mapas efetuou-se a hierarquização da rede de drenagem, conforme critério proposto por STRAHLER (1952). Em trabalhos realizados na região do Alto Estrutural de Queluz (SALVADOR \& RICCOMINI 1995) e na região de Altamira - PA (RODRIGUEZ 1993), tais técnicas mostraram-se eficazes na análise neotectônica, permitindo individualizar setores anômalos e descontinuidades.

O mapa de superfícies de base (Filosofov 1960 apud JAIN 1984, GOLTS \& ROSENTHAL 1993) possibilita identificar contrastes acentuados no padrão de relevo de uma área, os quais podem indicar manifestações de eventos erosivo-tectônicos regionais e, em especial, de movimentações recentes da crosta. Para a elaboração deste mapa, obtiveram-se manualmente os pontos de intersecção dos canais de drenagem de $2^{\text {a }}$ ordem com as curvas de nível.

Já o mapa de gradientes hidráulicos, conforme a proposição de RODRIGUEZ (1993), permite separar blocos com características hidráulicas distintas, numa tentativa de correlacioná-los com lineamentos estruturais. Para a elaboração deste mapa, obteve-se manualmente o gradiente hidráulico para cada drenagem de $2^{\mathrm{a}}$ ordem, a partir da razão da diferença altimétrica entre a cabeceira e a foz de cada drenagem com o comprimento em planta do canal; os valores obtidos foram atribuídos às porções médias das drenagens.

A densidade de drenagem, definida inicialmente por HORTON (1945), permite a individualização de áreas anômalas de alta ou baixa densidade de drenagem, que podem estar refletindo controle neotectônico. Para a aquisição dos dados foi estabelecida uma malha quadrática de amostragem composta por células de 500 $\mathrm{X} 500 \mathrm{~m}$ no programa IDRISI (Clark University). A densidade de drenagem foi obtida para cada célula a partir da razão entre a somatória do comprimento total da rede de drenagem e sua área (constante $=0,25 \mathrm{~km}^{2}$ ), atribuindo-se o valor obtido para o centro de cada célula. $\mathrm{O}$ mesmo procedimento foi adotado para a elaboração do mapa de densidade de lineamentos, utilizando-se, neste caso, mapas de lineamentos morfoestruturais obtidos das imagens de satélite, de radar e dos mapas de sombreamento de relevo.

O parâmetro rugosidade do relevo vem sendo empregado para caracterização morfométrica de terrenos cársticos (DAY 1979, HOBSON 1972, FERRARI et al. 1998). Neste trabalho pretendeu-se verificar a relação entre a rugosidade do relevo e eventos de deformação tectônica recente. Para a aquisição dos dados estabeleceu-se uma malha de amostragem com células quadráticas de $1 \times 1 \mathrm{~km}$. A rugosidade foi obtida para cada célula a partir da relação entre área real e área planar. Deste modo, valores próximos à unidade indicam áreas de relevo muito plano, enquanto que valores maiores, áreas de relevo mais acidentado.

A apresentação dos mapas de isovalores dos parâmetros morfométricos foi gerada no programa SURFER (Golden Software). Correlações entre os parâmetros morfométricos foram obtidas no programa IDRISI (Clark University), empregando-se o modelo de regressão linear.

\section{CORRELAÇÃO ENTRE PARÂMETROS MORFOMÉTRICOS E DADOS GEOMORFOLÓGICO-ESTRUTURAIS}

A análise de lineamentos morfoestruturais indica a presença das seguintes direções: NESW, ENE-WSW, N-S e NW-SE (Fig. 3). As direções NE-SW e ENE-WSW são coerentes com a estruturação regional pré-cambriana dada pelas foliações metamórficas (xistosidade, bandamento e foliação milonítica) e pelas zonas de cisalhamento (Jundiuvira, Paiol Grande e Buquira), constituindo zonas preferenciais de reativação por falhas com componente normal. Morfologicamente estão expressas pelo alinhamento de escarpas, cristas e vales retilíneos da drenagem subseqüente do planalto. As direções N-S e NW-SE têm sua origem relacionada a uma estruturação mais recente e correspondem, na maior parte dos casos, a falhas com componente transcorrente que deslocam cristas e escarpas de direção NE-SW/ENE-WSW e, por vezes, condicionam a drenagem conseqüente do planalto. Essas falhas estão associadas a diferentes regimes de esforços neotectônicos (HIRUMA 1999) correlacionáveis com áreas vizinhas, como por exemplo na região do Alto Estrutural de Queluz (SALVADOR \& RICCOMINI 1995) e no Vale do Rio Paraíba do Sul (RICCOMINI 1989).

A visão realística do modelo digital de ter- 

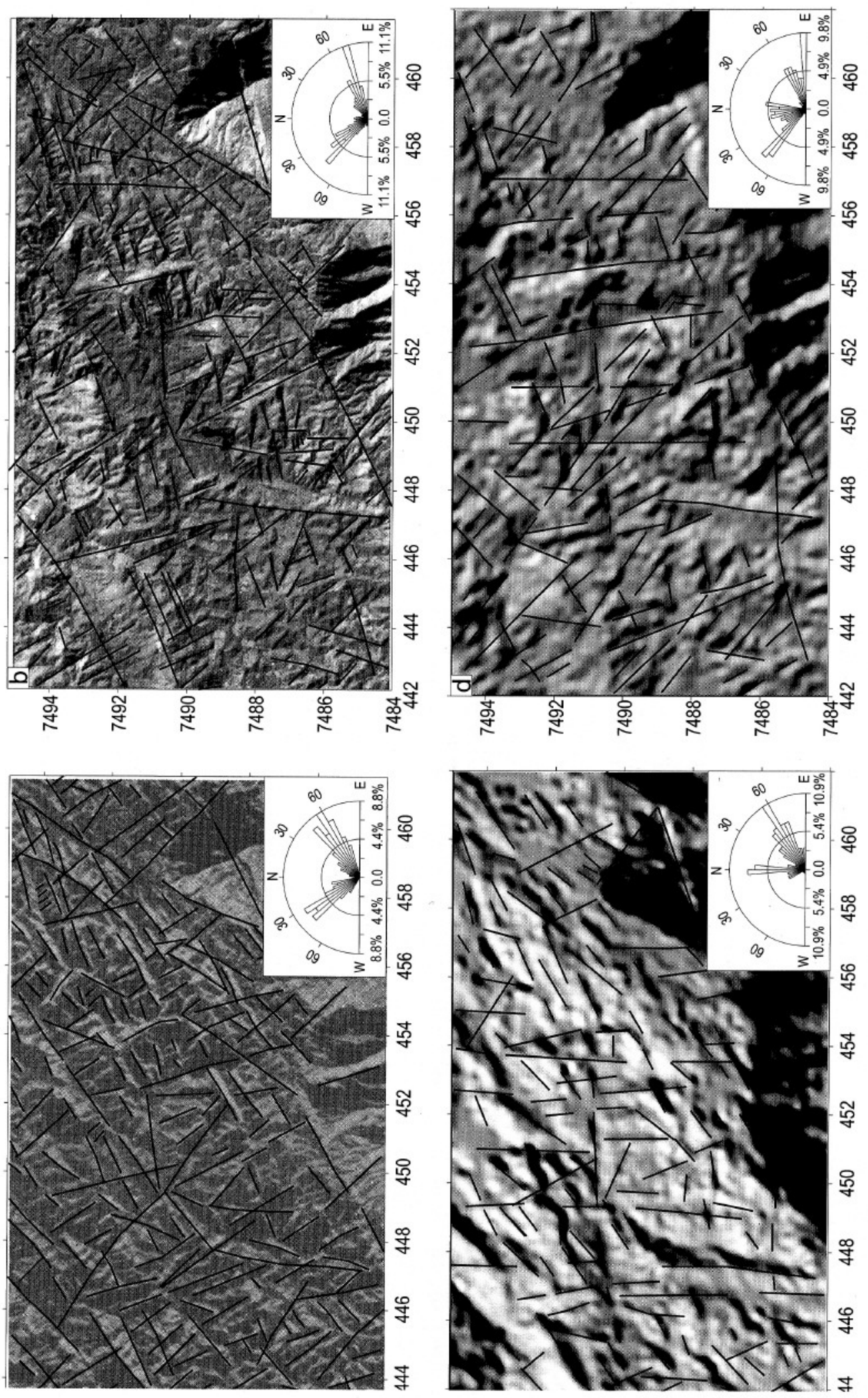

FIGURA 3 - Diagramas de rosácea de fotolineamentos interpretados a partir de (a) mosaico semicontrolado de radar (azimute $=90^{\circ}$ ), (b) imagem de satélite Landsat 5, Banda 4 (azimute $47^{\circ}$, elevação $30^{\circ}$ ), (c) imagem de sombreamento de relevo (azimute $315^{\circ}$, elevação $45^{\circ}$ ), (d) imagem de sombreamento de relevo (azimute $45^{\circ}$, elevação $30^{\circ}$ ). Diagramas de rosáceas elaborados pelo programa ROSAC (IPT). 
reno (MDT, Fig. 4) mostra os diferentes níveis topográficos e as principais feições morfológicas da área de estudo. As porções mais elevadas da área de estudo (1.900 a $2.007 \mathrm{~m}$ ) e com as menores amplitudes topográficas situam-se na área dos campos de São Francisco. Para noroeste, a altitude decresce, até atingir cotas abaixo de $1.300 \mathrm{~m}$ no Ribeirão dos Marmelos (Fig. 5a). No geossistema serrano as formas de relevo apresentam amplitudes e declividades mais elevadas. A presença de tectonismo recente é sugerida por diversas feições morfológicas. Uma das feições mais marcantes é o alinhamento de escarpas retilíneas e cristas de direções
ENE-WSW/ NE-SW, com amplitudes que variam de 20 a 70 m nos campos de São Francisco a 150 $200 \mathrm{~m}$ no geossistema serrano. Falhas N-S com componente transcorrente sinistral são responsáveis por fenômenos de captura de drenagem e surgimento de divisores pouco nítidos e shutter ridges (MODENESI-GAUTTIERI et al. 1997a,b, HIRUMA 1999). O processo de denudação das escarpas fez surgir, em estágios mais avançados, facetas triangulares e trapezoidais (Fig. 4). Os festões da escarpa da Serra da Mantiqueira correspondem a prolongamentos de falhas recentes de direções NE-SW e NW-SE (Fig. 2).

Os parâmetros estatísticos dos índices morfométricos podem ser observados na Tabela 1 .

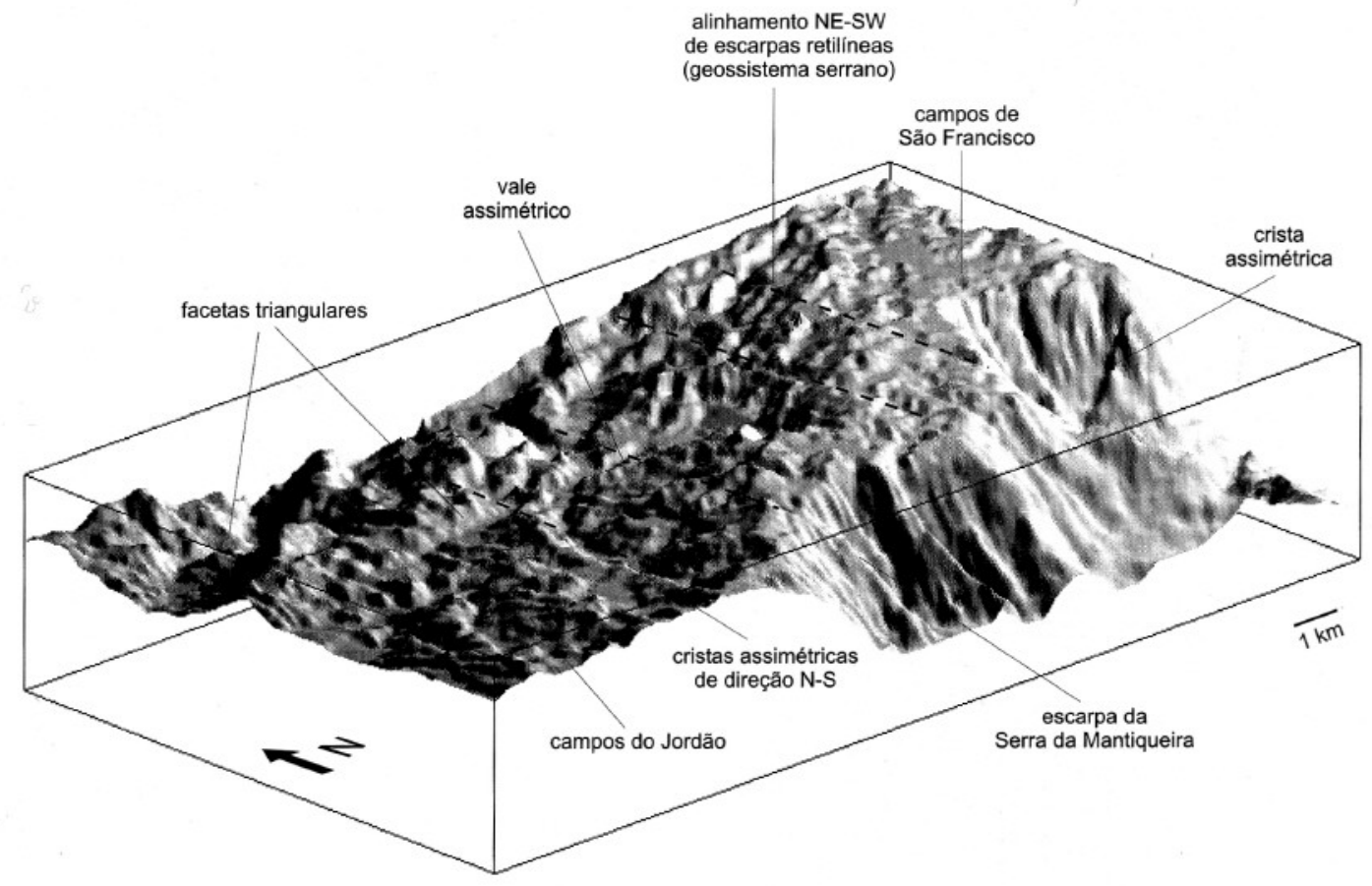

FIGURA 4 - Modelo digital de terreno (MDT) destacando o escalonamento de níveis topográficos e as principais feições morfológicas (exagero vertical $=2,5$ ). Em tracejado, fotolineamentos de direção NW-SE/N$\mathrm{S}$ relacionados a transcorrência sinistral. Limites da área de estudo: Xmín., Xmáx. $(\mathrm{m})=442000,461500$; Ymín., Ymáx. $(\mathrm{m})=7484000,7495000$; Zmín., Zmáx. $(\mathrm{m})=735859,2006.84$. 


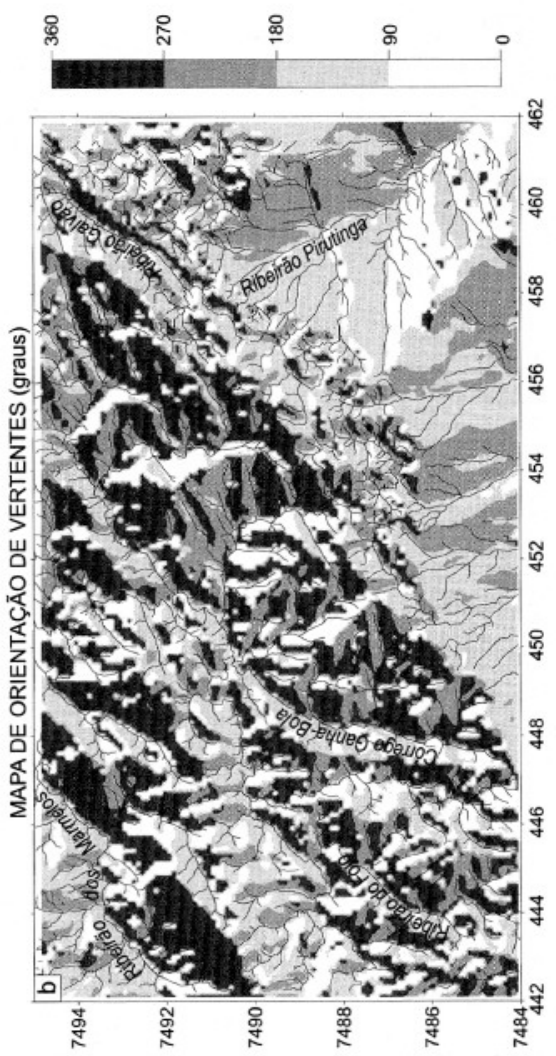

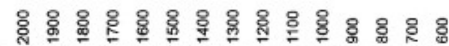

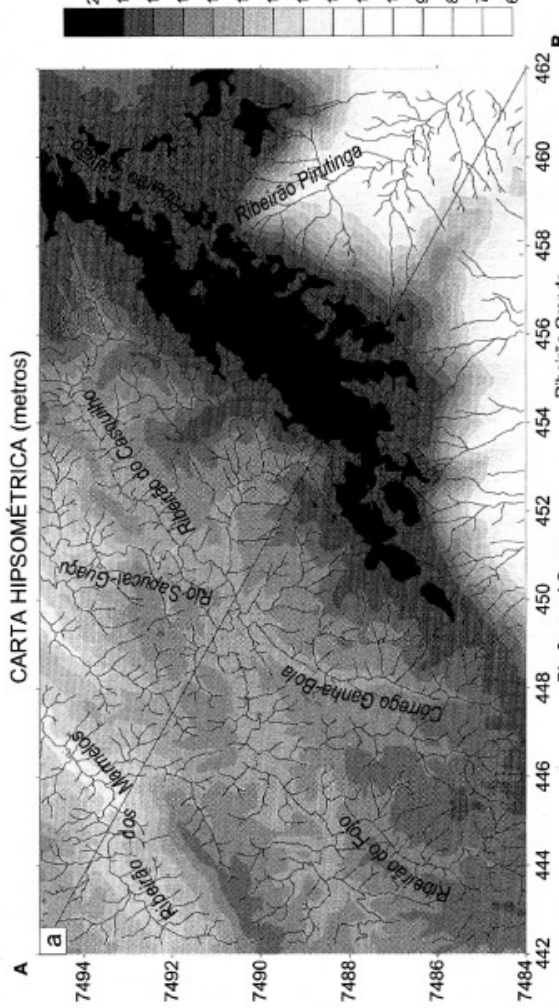

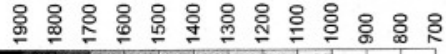

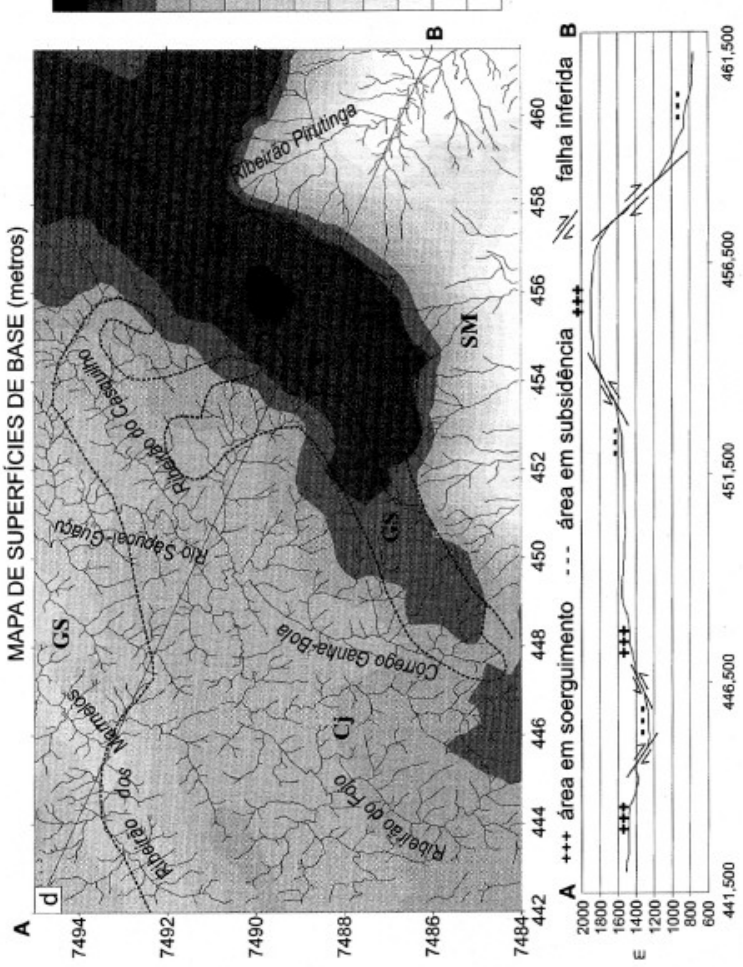

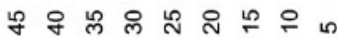
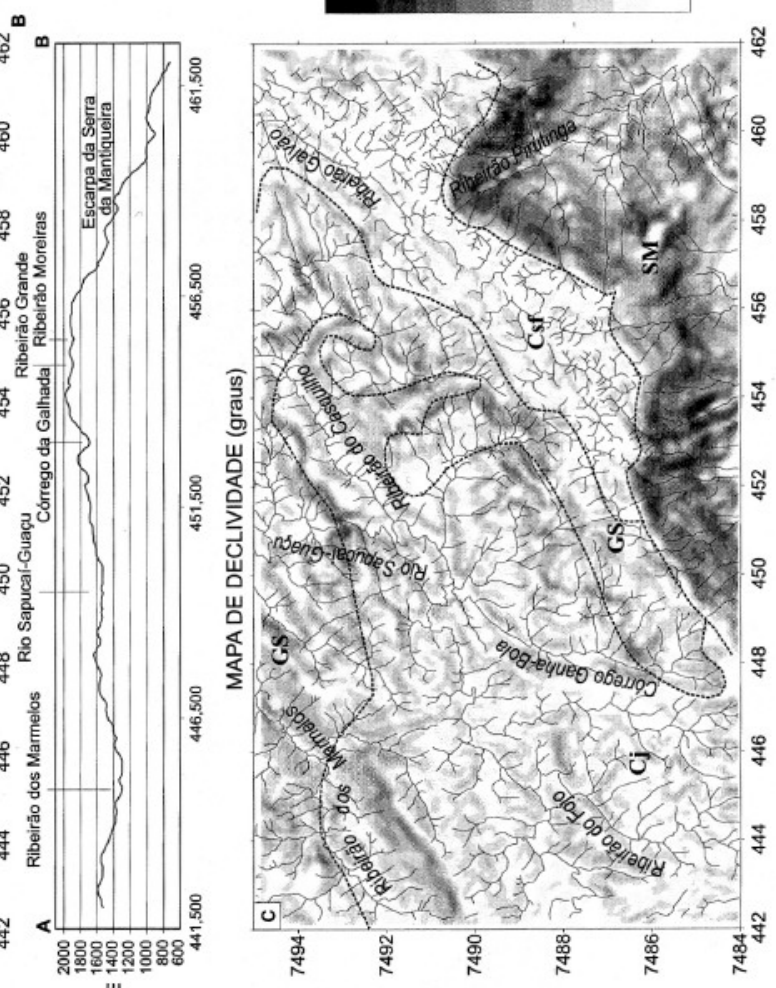

FIGURA 5 - (a) carta hipsométrica, (b) mapa de orientação de vertentes (em graus), (c) mapa de declividade (graus), (d) mapa de superfícies de base (metros). 
Neste trabalho são considerados arbitrariamente como anômalos valores acima e abaixo da média $+/$ - desvio padrão.

A análise conjunta dos mapas de orientação

\begin{tabular}{|l|c|c|c|c|}
\hline PARÂMETRO & $\begin{array}{c}\text { Valor } \\
\text { mín. }\end{array}$ & $\begin{array}{c}\text { Valor } \\
\text { máx. }\end{array}$ & Média & $\begin{array}{c}\text { Desvio } \\
\text { Padrão }\end{array}$ \\
\hline Densidade de drenagem & 0 & 6,3743 & 2,8154 & 1,2031 \\
\hline Densidade de lineamentos & 0 & 4,475 & 1,3015 & 1,0025 \\
\hline Gradiente hidráulico & 0 & 0,7557 & 0,1519 & 0,1224 \\
\hline Rugosidade de relevo & 1,0031 & 1,1882 & 1,0456 & 0,0349 \\
\hline
\end{tabular}

TABELA 1 - Parâmetros estatísticos dos índices morfométricos.

de vertentes (Fig. 5b) e de declividade (Fig. 5c) ilustra o caráter assimétrico das formas de relevo, representadas pela seqüência de vales assimétricos e escarpas retilíneas com vertentes abruptas voltadas para sudeste, de direção NESW e ENE-WSW. Este conjunto é truncado por alinhamentos de direção N-S e NW-SE, coincidentes com trechos dos ribeirões GanhaBola, Fojo, Casquilho (nascente), Serrote e Galhada. Os maiores valores de declividade $\left(>30^{\circ}\right)$ ocorrem na escarpa da Serra da Mantiqueira e em alguns setores do geossistema serrano e correspondem aos alinhamentos de cristas quartzíticas e escarpas mais proeminentes (Fig. 5c), enquanto que os menores valores de declividade $\left(<10^{\circ}\right)$ ocorrem nos campos de São Francisco.

A análise do mapa de superfícies de base (Fig. 5d) permitiu a identificação de três domínios distintos, delimitados pelos seguintes intervalos:

a) entre 800 a $1.800 \mathrm{~m}$, com as maiores concentrações de curvas de superfícies de base, correspondente às escarpas da Serra da Mantiqueira;

b) entre 1.850 a $2.000 \mathrm{~m}$, caracterizado pela presença de superfícies de base bem espaçadas, coincidindo aproximadamente com os limites dos campos de São Francisco;

c) entre 1.500 a $1.700 \mathrm{~m}$, coincidindo aproximadamente com a área de abrangência dos campos do Jordão. A transição entre este domínio e o anterior corresponde aproximadamente aos limites do geossistema serrano.

A distribuição desses três domínios sugere uma compartimentação em blocos do planalto, com abatimentos para NW. Os campos de São Francisco corresponderiam a uma área de soerguimento mais pronunciado, enquanto que os setores da escarpa da Serra da Mantiqueira e do Ribeirão dos Marmelos, de subsidência.

Observa-se uma significativa correlação espacial das anomalias de alta e baixa densidade de drenagem com a distribuição de estruturas reativadas no Cenozóico de direções NE-SW e NW-SE (Fig. 6a). Do ponto de vista estritamente litológico não foi possível explicar a distribuição espacial da densidade de drenagem. As maiores concentrações de zonas de alta densidade de drenagem $\left(>4 \mathrm{~km} / \mathrm{km}^{2}\right)$ ocorrem na região dos campos de São Francisco, área com grande concentração de feições morfotectônicas, sugerindo uma retomada erosiva das formas de relevo, com formação de novos canais. Conforme modelo proposto por JIANJUN et al. (1997), que relaciona o comportamento da densidade de drenagem linear e areal com taxas de soerguimento e subsidência tectônica, a área dos campos de São Francisco estaria em estágio intermediário a final de soerguimento, quando a intensidade de soerguimento é igual ou mais baixa que a incisão do canal. Nesta situação desenvolve-se uma nova rede de ravinas no bloco em soerguimento, devido à erosão remontante, levando à formação de um padrão de drenagem denso, radial, com muitos canais estreitos. A figura 7 ilustra a distribuição da densidade de drenagem na topografia. MELO et al. (1993) e HIRUMA \& PONÇANO (1994) verificaram na região do Alto Rio Pardo (SP - MG) que as principais anomalias de adensamento de drenagem apresentavam estreita correlação com 
운
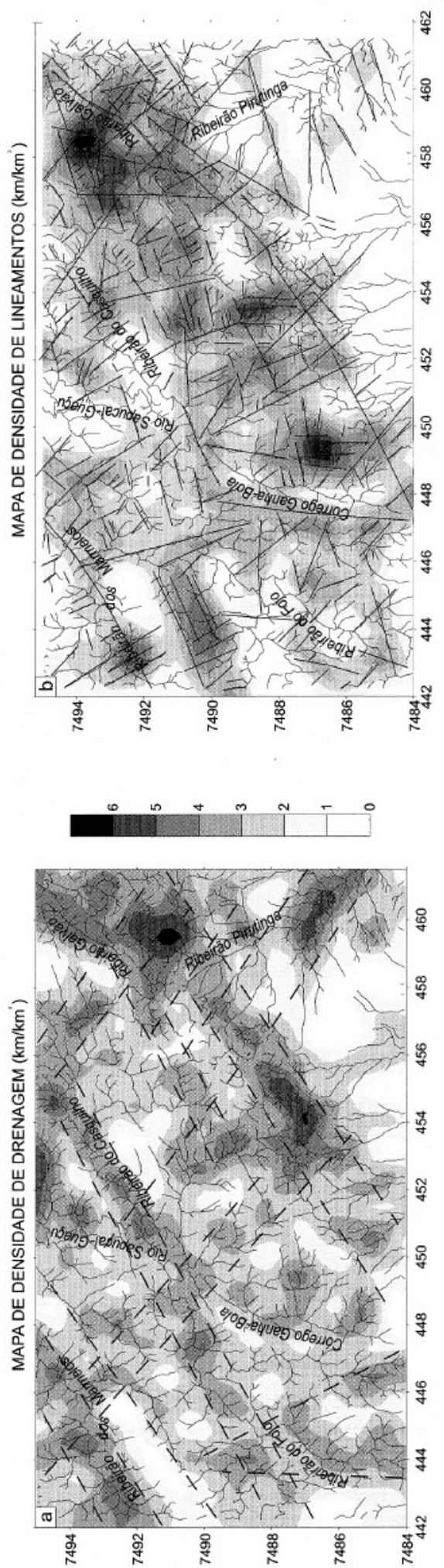

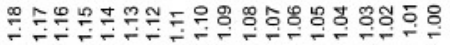

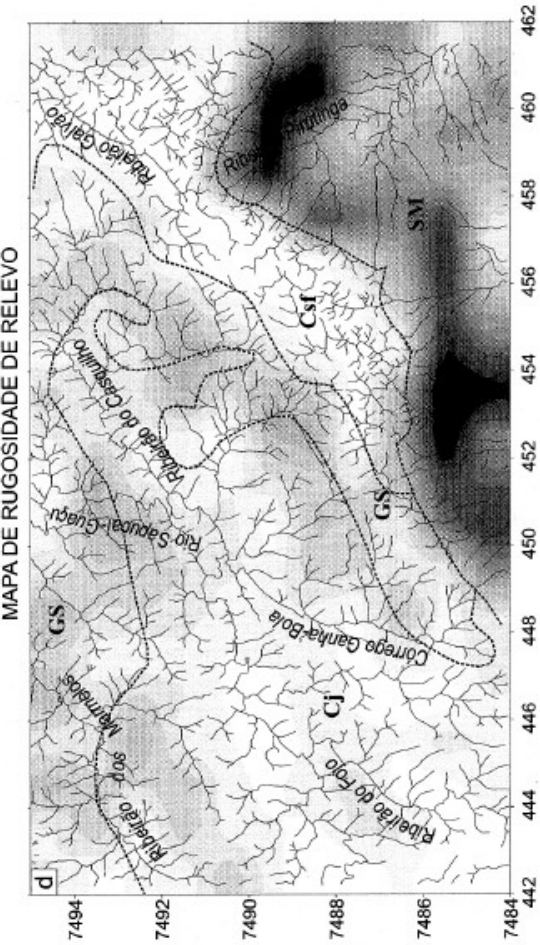

$\stackrel{0}{0}$ 人ิ

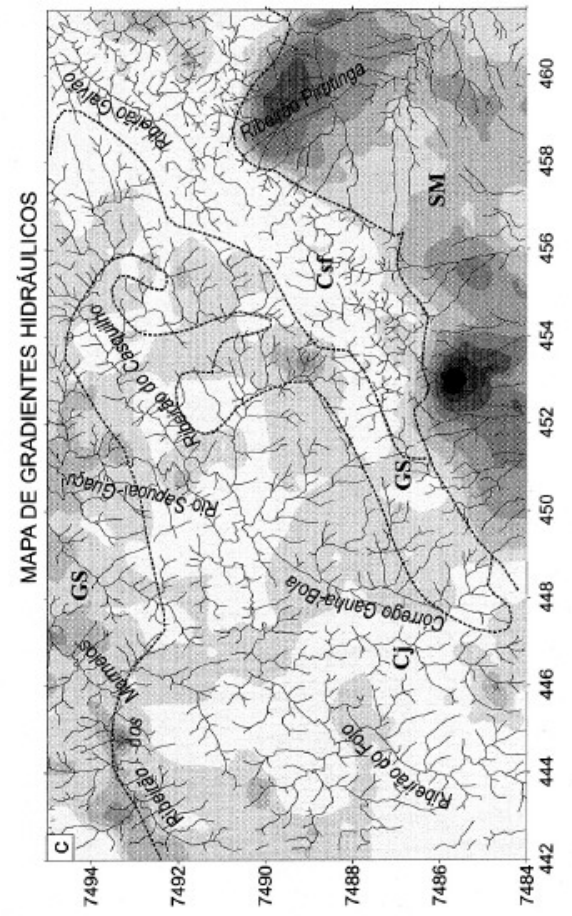

FIGURA 6 - (a) mapa de densidade de drenagem $\left(\mathrm{km} / \mathrm{km}^{2}\right)$, b) mapa de densidade de lineamentos $\left(\mathrm{km} / \mathrm{km}^{2}\right)$, (c) mapa de gradientes hidráulicos, (d) mapa de rugosidade de relevo. 
blocos topograficamente soerguidos delimitados por estruturas, sugerindo rejuvenescimento do relevo ao longo dessas direções.

Os maiores valores de densidade de linea-

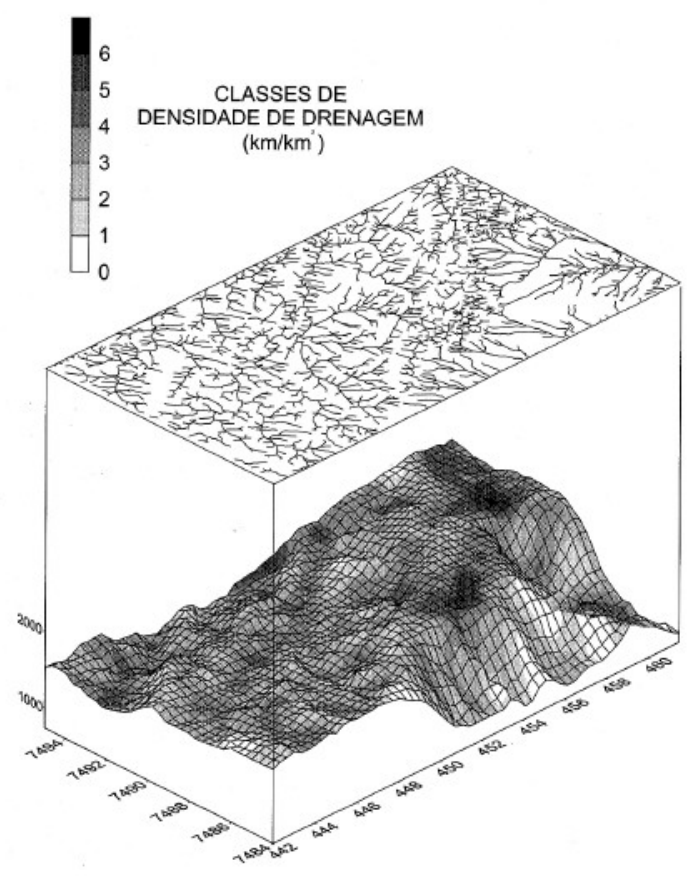

FIGURA 7 - Distribuição da densidade de drenagem $\left(\mathrm{km} / \mathrm{km}^{2}\right.$, malha quadrática de $\left.500 \times 500 \mathrm{~m}\right)$ na topografia (MDT).

mentos $\left(>2,3 \mathrm{~km} / \mathrm{km}^{2}\right)$ concentram-se principalmente no geossistema serrano e nos campos de São Francisco, coincidindo com as áreas de intersecção das principais direções de lineamentos (NE-SW, ENE-WSW, N-S e NW-SE, Fig. $6 b)$. A elevada densidade de drenagem observada nestas áreas possivelmente é atribuída à geração de descontinuidades por basculamentos tectônicos. Níveis de soleiras estão condicionados ao cruzamento dos principais lineamentos (HIRUMA 1999).

As distribuições espaciais dos parâmetros de gradientes hidráulicos (Fig. 6c) e rugosidade de relevo (Fig. 6d) guardam uma grande semelhança com os limites de unidades geossistêmicas estabelecidas para o planalto. Os maiores valores de gradiente hidráulico $(>0,3)$ estão situados na escarpa da Mantiqueira, enquanto que os menores valores $(<0,1)$, nos campos de São Francisco. Valores intermediários são encontrados no geossistema serrano $(0,1$ a 0,3$)$ e nos campos do Jordão $(0,0$ a 0,2$)$. As áreas mais planas (índices de rugosidade próximos a $1,00)$ correspondem aos campos de São Francisco, enquanto que as áreas com maior rugosidade de relevo situam-se no geossistema serrano (indice entre 1,03 e 1.06) e nas escarpas da Serra da Mantiqueira (índice $>1,11$ ). No caso específico do Planalto de Campos do Jordão, o parâmetro rugosidade do relevo reflete principalmente a amplitude dos desníveis topográficos gerados por basculamentos tectônicos.

A partir da análise de regressão linear foi possível estabelecer índices de correlação entre os diversos parâmetros. O melhor índice de correlação $(r=0,82)$ foi obtido entre os parâmetros rugosidade de relevo (variável dependente) e gradiente hidráulico (variável independente) (Fig. 8). Outras correlações utilizando o modelo linear não apresentaram bons índices de determinação; no entanto, algumas tendências foram observadas: o aumento da densidade de lineamentos é acompanhado pelo aumento da densidade de drenagem e diminuição da rugosidade de relevo; o aumento do gradiente hidráulico é acompanhado pela diminuição das densidades de drenagem e de lineamentos.

Verificou-se uma estreita correlação entre

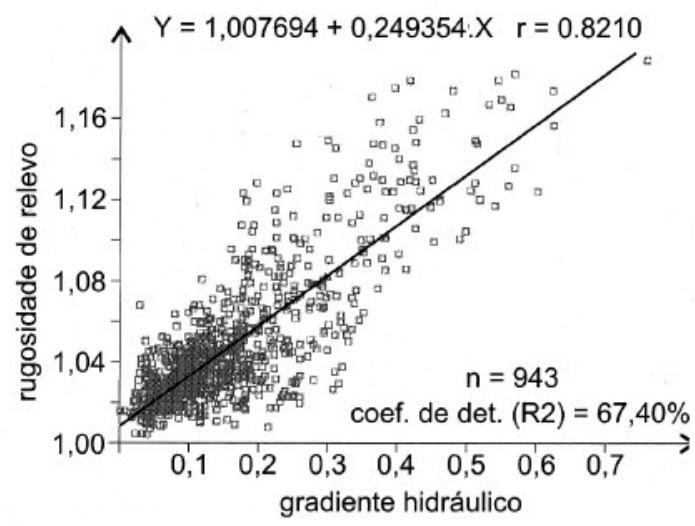

FIGURA 8 - Gráfico de correlação entre gradiente hidráulico e rugosidade de relevo.

mapas morfométricos (superfícies de bases, gradientes hidráulicos e rugosidade de relevo), estruturas reativadas no Cenozóico e limites de unidades geossistêmicas estabelecidos por MODENESI (1988a). Alguns limites entre geossistemas (por exemplo, entre o geossistema serrano e os campos de São Francisco) são bruscos e acompanham as direções de falhas reativadas. Cabe ressaltar que estas unidades foram estabelecidas a partir das características de formas de relevo, formações superficiais e 
vegetação. A tectônica recente teve um importante papel na evolução geomorfológica, que por sua vez se refletiu na definição das diferentes unidades de paisagem. O controle litológico teve um papel subordinado.

\section{CONCLUSÕES}

Os métodos utilizados permitiram identificar padrões anômalos condicionados pela tectônica recente, expressos na rede de drenagem e nas formas de relevo. As escalas de trabalho 1:10.000 e 1:50.000 - mostraram-se adequadas para a análise. $\mathrm{O}$ uso de técnicas de geoprocessamento possibilitou a obtenção de parâmetros morfométricos e análises de correlação com maior precisão e rapidez. Cabe ressaltar, no entanto, que as análises morfométricas foram realizadas a partir de cartas topográficas, que podem apresentar imperfeições inerentes aos procedimentos de harmonização impostos pelo cartógrafo ao traçado das curvas de nível, como aquelas decorrentes da própria restituição das fotos aéreas (PONÇANO et al. 1989).

Mapas de sombreamento de relevo e modelos digitais de terreno auxiliaram na identificação dos principais lineamentos morfoestruturais, complementando a interpretação de sensores remotos, além de ressaltar as principais feições morfológicas. As direções NE - SW e ENE WSW são coerentes com a estruturação regional pré-cambriana, enquanto que as direções $\mathrm{N}$ - $\mathrm{S}$ e NW - SE refletem uma estruturação mais recen- te. O arranjo ortogonal dos lineamentos subdivide o Planalto de Campos do Jordão em blocos menores.

A análise morfométrica, em conjunto com a análise estrutural, evidencia um importante controle tectônico, presente na organização da rede de drenagem e na compartimentação em blocos do planalto. Como esperado, a compartimentação estabelecida coincide, muitas vezes, com os limites de unidades geossistêmicas do planalto, uma vez que estas são integradoras dos vários parâmetros controladores da paisagem. Entretanto, no presente estudo foi possível ressaltar e confirmar o importante papel da tectônica recente na configuração atual do relevo.

No Planalto de Campos do Jordão, os resultados da análise morfométrica mostraram boa correlação com as informações estruturais e geomorfológicas. Em regiões que não dispõem de estudos geológicos e geomorfológicos básicos, a aplicação desta metodologia constitui uma importante ferramenta que pode preceder os trabalhos de campo.

\section{AGRADECIMENTOS}

Os autores agradecem o apoio financeiro e científico proporcionado pela FAPESP (Processo 96/08239-5). Agradecem também aos pesquisadores científicos Drs. José Antonio Ferrari e May Christine Modenesi pelas importantes críticas e sugestões apresentadas.

\section{REFERÊNCIAS BIBLIOGRÁFICAS}

AB'SÁBER, A. N. 1956. A terra paulista. São Paulo: Boletim Paulista de Geografia, 23: 5-38.

\& BERNARDES, N. 1958. Vale do Paraíba, Serra da Mantiqueira e arredores de São Paulo. In: CONGRESSO INTERNACIONAL DE GEOGRAFIA, 18, Rio de Janeiro, RJ. Guia de Excursões... Rio de Janeiro, RJ. CNG, v.4, 304 p.

ALMEIDA, F.F.M. de. 1964. Fundamentos geológicos do relevo paulista. São Paulo: Boletim do Instituto Geográfico e Geológico, 41: 169-263.
ALMEIDA, F.F.M. de. 1967. Origem e evolução da Plataforma Brasileira. Rio de Janeiro, DNPM/DGM, 241, 36 p.

1976. The system of continental rifts bordering the Santos Basin, Brazil. Rio de Janeiro: Anais da Academia Brasileira de Ciências, 48 (Suplemento): $15-26$.

HASUI, Y.; BRITO NEVES, B.B. de. 1976. The Upper Precambrian of South America. São Paulo: Boletim do Instituto de Geociências - USP, 7: 5-80.

ASMUS, H.E. \& FERRARI, A.L. 1978. Hipótese sobre a causa do tectonismo 
cenozóico na região sudeste do Brasil. Projeto REMAC, 4, p. 75 - 88.

CAVALCANTE, J.C.; CUNHA, H.C.S.; CHIEREGATI, L.A.; KAEFER, L.Q.; ROCHA, J.M.; DAITX, E.C.; COUTINHO, M.G.N.; YAMAMOTO, K.; DRUMOND, J.B.V.; ROSA, D.B.; RAMALHO, R. 1979. Projeto Sapucaí. Estados de Minas Gerais e São Paulo. Relatório Final de Geologia. DNPM/CPRM, Brasil, 299p. (Série Geologia $n^{\circ}$ 5, Seção Geologia Básica $\mathrm{n}^{\circ 2}$ ).

DAY, M.J. 1979. Surface roughness as a discriminator of tropical karst styles. Berlin: Zeitschrift für Geomorphologie, Supplement 32: 1-8.

DEFFONTAINES, B. 1989. Proposition of a morpho-neotectonic method; application in the Fougères area, Oriental Britany, France. Bull. INQUA, N.C.12, p. 48-52.

1990. Digital terrain model and morpho-neotectonics application in the Strasbourg area, Rhine graben, France. Bull. INQUA, N.C.13, p. 58-59.

1991. Contribution of drainage network analysis to neotectonics: method and application in France. Bull. INQUA, N.C. 14: 16-17.

DE MARTONNE, E. 1943. Problemas morfológicos do Brasil tropical Atlântico. São Paulo: Revista Brasileira de Geografia, 4: 523-550.

DEROIN, J. \& DEFFONTAINES, B. 1995. Morphostructural analysis for linking streamflow, lithology, and structure: comparison with remote sensing data on the Cévennes (French Massif Central). Berlin: Zeitschrift für Geomorphologie, 39 (1): 97-116.

FERRARI, J.A. \& MANGIN, A. 2000. Visualização e análise espacial de sistemas cársticos. In: SIMPÓSIO DE QUANTIFICAÇÃO EM GEOCIÊNCIAS, 8, Rio Claro, SP. Boletim de Resumos Expandidos..., Rio Claro, SP. IGCE-UNESP, p. 95-97.

FERRARI, J.A.; HIRUMA, S.T.; KARMANN, I. 1998. Caracterização morfométrica de uma superfície cárstica do Vale do Ribeira, São Paulo (Núcleo Caboclos PETAR). São Paulo: Revista do Instituto Geológico, 19(1/2): 9-17.
FREITAS, R.O. de. 1951. Ensaio sobre a tectônica moderna do Brasil. São Paulo: Faculdade de Filosofia, Ciências e Letras - USP, 120 p. (Boletim 130, Geologia 6).

GOLTS, S. \& ROSENTHAL, E. 1993. A morphotectonic map of the northern Arava in Israel, derived from isobase lines. Amsterdam: Geomorphology, 7: 305-315.

GONTIJO, A.H.F.; BORGES, M. da S.; HASUI, Y.; COSTA, J.B.S.; JIMENEZRUEDA, J.R. 1998. Morfoestrutura, morfotectônica e modelagem digital de terreno da região da Serra da Bocaina. São Paulo: Geociências, 17(1): 137-159.

HASUI, Y.; PONÇANO, W.L.; BISTRICHI, C.A.; STEIN, D.P.; GALVÃO, C.A.C.F.; GIMENEZ, A.F.; ALMEIDA, M.A. de; PIRES NETO, A.G.; MELO, M.S. de; SANTOS, M.C.S.R. dos. 1978. Geologia da Região Administrativa 3 (Vale do Paraíba) e parte da Região Administrativa 2 (Litoral) do Estado de São Paulo. São Paulo: Instituto de Pesquisas Tecnológicas, São Paulo, 2v. (Monografias).

HIRUMA, S.T. 1999. Neotectônica no Planalto de Campos do Jordão, SP. Dissertação de mestrado, Instituto de Geociências - USP, $102 \mathrm{p}$.

\& PONÇANO, W.L. 1994. Densidade de drenagem e sua relação com fatores geo-morfo-pedológicos na área do Alto Rio Pardo, SP e MG. São Paulo: Revista do Instituto Geológico, 15(1/2): 49-57.

HOBSON, R.D. 1972. Surface roughness in topography: quantitative approach. In: CHORLEY, R.J. (ed) Spatial analysis in geomorphology. Harper and Row, p.225-245.

HORTON, R.E. 1945. Erosional development of streams and their drainage basins: hydrophysical approach to quantitative morphology. Colorado: Geological Society of American Bulletin, 56 (3): $275-370$.

JAIN, V.E. 1984. Geotectónica general. Moscou, vol. 1, 357 p.

JIANJUN, H.; MUKANG, H.; OLLIER, C.D. 1997. A morphometric method to determine neotectonic activity of the Weihe Basin in northwestern China. Episodes, 20(2): 95-99. 
JOHANSSON, M. 1999. Analysis of digital elevation data for palaeosurfaces in southwestern Sweden. Amsterdam: Geomorphology, 26: 279-295.

LIU, C.C. 1987. A geologia estrutural do Estado do Rio de Janeiro vista através de imagens MSS do Landsat. Anais do I Simpósio de Geologia Regional RJ-ES, SBG, p. $164-188$.

MELO, M.S. de; STEIN, D.P.; PONÇANO, W.L.; BISTRICHI, C.A. 1993. Neotectônica da área do Alto Rio Pardo (SP e MG). São Paulo: Revista do Instituto Geológico, 14(2), 27-38.

MODENESI, M.C. 1980. Intemperismo e morfogênese no Planalto de Campos do Jordão, São Paulo. São Paulo: Revista Brasileira de Geociências, 10(3):213-225.

1983. Weathering and morphogenesis in a tropical plateau. Amsterdam: Catena, 10(3):237-251.

1988a. Significado dos depósitos correlativos quaternários em Campos do Jordão - São Paulo: implicações paleoclimáticas e paleoecológicas. São Paulo: Instituto Geológico, 155 p. (Boletim 7).

1988b. Quaternary mass movements in a tropical plateau (Campos do Jordão, São Paulo, Brazil). Berlin: Zeitschrift für Geomorphologie, 32(4):425-440.

MODENESI-GAUTTIERI, M.C.; HIRUMA, S.T.; RICCOMINI, C. 1997a. Geomorphological evolution and tectonic reactivation in a tropical plateau (Campos do Jordão, SE Brasil). In: International Conference on Geomorphology, 4, Bologna, Italia. Supplement di Geografia Fisica e Dinamica Quaternaria, Supplemento III (Tomo 1), p. 278.

1997b. Morfotectônica dos altos Campos de São Francisco (Planalto de Campos do Jordão - SP). In: SIMPÓSIO DE GEOLOGIA DO SUDESTE, 5, Penedo, RJ. Atas... Penedo, RJ, SBG/ABGE, p. 77-79.

MORAIS, S.M.; DEHLER, N.M.; SACHS, L.L.B.; RODRIGUES, J.B. Inédito. Carta geológica - Folha Guaratinguetá (SF.23Y-B), escala 1:250.000. CPRM Superintendência Regional de São Paulo, Programa Levantamentos Geológicos Básicos do Brasil.
PONÇANO, W.L.; MELO, M.S. de; CHRISTOFOLETTI, A. 1989. Relações entre deflúvios e variáveis morfométricas em bacias hidrográficas do Estado de São Paulo. São Paulo: Revista Brasileira de Geociências, 19(2): 197-206.

RICCOMINI, C. 1989. O rift continental do sudeste do Brasil. Tese de Doutoramento, Instituto de Geociências - USP, 256 p.

\& CRÓSTA, A.P. 1988. Análise preliminar de lineamentos em imagens de sensores remotos aplicada à prospecção mineral na área dos granitóides Mandira, SP. São Paulo: Boletim do Instituto de Geociências - USP, Série Científica, 19: 23-37.

RILEY, C. \& MOORE, J.M. 1993. Digital elevation modelling in a study of the neotectonic geomorphology of the Sierra Nevada, southern Spain. Berlin: Zeitschrift für Geomorphologie, Suplement 94 (Neotectonics and active faulting), p. 25 - 39.

RODRIGUEZ, S.K. 1993. Neotectônica e sedimentação quaternária na região da "Volta Grande" do Rio Xingu, Altamira, Pará. Dissertação de Mestrado, Instituto de Geociências - USP, 106 p.

RUELLAN, F. 1952. Excursão à região do Vale do Paraíba e à Serra da Mantiqueira. Guia de excursão. B. I Reunião Panamericana. Consulta sobre Geogr., set./1949, Anais, 2, p. 206-251.

SAADI, A. 1991. Ensaio sobre a morfotectônica de Minas Gerais: tensões intra-placa, descontinuidades crustais e morfogênese. Tese Professor Titular - Departamento de Geografia, Instituto de Geociências UFMG, $285 \mathrm{p}$.

SALVADOR, E.D. \& RICCOMINI, C. 1995. Neotectônica da região do Alto Estrutural de Queluz (SP-RJ, Brasil). São Paulo: Revista Brasileira de Geociências, 25 (3): 151-164.

SCHOBBENHAUS, C.; CAMPOS, D. de A.; DERZE, G.R.; ASMUS, H.E. 1984. Geologia do Brasil. Texto explicativo do Mapa Geológico do Brasil e da área oceânica adjacente incluindo depósitos minerais - escala 1:2.500.000. MME/DNPM, Brasília, 501 p. 
STRAHLER, A.N. 1952. Dynamic basis of geomorphology. Colorado: Geological Society of American Bulletin, 63: 923-938.

ZUCHIEWICZ, W. 1991. On different approaches to neotectonics: a Polish Carpathians example. Episodes, 14(2):116-124.
ZUCHIEWICZ, W. \& OAKS Jr., R.Q. 1993. Geomorphology and structure of the Bear River Range, north eastern Utah: a morphometric approach. Berlin: Zeitschrift für Geomorphologie, Suplement 94 (Neotectonics and active faulting), p. $41-55$.

Trabalho produzido com apoio financeiro da Fundação de Amparo à Pesquisa do Estado de São Paulo Fapesp (Processo 96/08239-5).

Endereço dos autores:

Silvio Takashi Hiruma - Instituto Geológico/SMA, Av. Miguel Stéfano 3.900, 04301-903, São Paulo, SP Brasil. E-mail: hiruma@igeologico.sp.gov.br

Claudio Riccomini - Instituto de Geociências, Universidade de São Paulo, Caixa Postal 11.348, 05422-970, São Paulo, SP - Brasil. E-mail: riccomin@usp.br 